\title{
Cannabis Use as Described by People with Multiple Sclerosis
}

\author{
S.A. Page, M.J. Verhoef, R.A. Stebbins, L.M. Metz, J.C. Levy
}

\begin{abstract}
Background: Multiple sclerosis (MS) is one of the most common neurological diseases affecting young adults. The prevalence of MS in Alberta has been described as among the highest reported in the world, estimated at 217 per 100,000. Numerous anecdotal reports, and a few small empirical investigations have suggested that cannabis use may relieve the symptom experience of those with MS. The present study was undertaken to describe cannabis use by this patient group. Information on peoples'beliefs, practices and experiences related to use were investigated. Methods: Aquestionnaire was mailed to a sample of 780 adults with MS in southern Alberta, Canada. Results: Completed questionnaires were returned by $420 / 673$ eligible subjects (response rate $62 \%$ ). Mean sample age was 48 years and $75 \%$ were women. Respondents ranged from mildly to severely impaired. The majority of respondents (96\%) was aware cannabis was potentially therapeutically useful for MS and most (72\%) supported legalization for medicinal purposes. Forty-three percent had tried cannabis at some point in their lives, $16 \%$ for medicinal purposes. Symptoms reported to be ameliorated included anxiety/depression, spasticity and chronic pain. Reasons given for not trying cannabis were the fact that it is an illegal substance, concern about side effects and lack of knowledge on how to obtain it. Conclusions: Subjective improvements in symptom experience were reported by the majority of people with MS who currently use cannabis. Further evaluation of this substance is warranted.
\end{abstract}

RÉSUMÉ: Utilisation du Cannabis par les patients atteints de sclérose en plaques. Introduction: La sclérose en plaques (SEP) est l'une des maladies neurologiques les plus fréquentes chez les jeunes adultes. La prévalence de la SEPen Alberta, estimée à 217 par 100000 , a été décrite comme l'une des plus élevées rapportées dans le monde. Plusieurs rapports anecdotiques et quelques études empiriques de petite taille ont suggéré que le l'utilisation de cannabis soulage les symptômes des patients atteints de SEP. Cette étude a été entreprise dans le but de décrire l'utilisation du cannabis chez ces patients. Nous avons évalué l'information sur les croyances, les pratiques et les expériences reliées à son utilisation. Méthodes: Un questionnaire a été posté à un échantillon de 780 adultes atteints de SEPrésidant dans le sud de l'Alberta, au Canada. Résultats: Quatre cent quarante des 673 sujets éligibles, soit un taux de réponse de $65 \%$, ont retourné le questionnaire complété. L'âge moyen des participants était de 48 ans et $75 \%$ étaient des femmes. L'invalidité chez les répondants était de légère à sévère. La majorité des répondants (96\%) savaient que le cannabis pouvait avoir une valeur thérapeutique dans la SEP et la plupart $(72 \%)$ étaient favorables à sa légalisation à des fins médicinales. Quarante-trois pour cent avaient essayé le cannabis à un moment ou l'autre de leur vie, dont $16 \%$ à des fins médicinales. Selon les utilisateurs, les symptômes qui étaient améliorés étaient l'anxiété/la dépression, la spasticité et la douleur chronique. Les raisons fournies pour ne pas avoir essayé le cannabis étaient le fait qu'il s'agit d'une substance illégale, l'inquiétude au sujet des effets secondaires et l'ignorance sur les moyens de s'en procurer. Conclusions: Une amélioration subjective de la symptomatologie a été rapportée par la majorité des patients qui utilisent actuellement le cannabis. Une évaluation plus poussée de cette substance dans ce contexte est justifiée.

Can. J. Neurol. Sci. 2003; 30: 201-205

Multiple sclerosis (MS) is a recurrent inflammation of the central nervous system white matter leading to myelin destruction and progressive neurological impairment. ${ }^{1}$ The prevalence of MS in Alberta has been described as high with an overall crude rate of 217 per 100,000 population. ${ }^{2}$ The available treatments for symptom management are of limited effectiveness and for many, have unpleasant side effects. ${ }^{3}$

Interest in cannabis as a therapeutic option for people with MS has coincided with the increasing acceptance of a wide variety of herbal and natural remedies. Most such substances lack medical endorsement due to a lack of empirical evidence for their efficacy and safety. ${ }^{4}$ The acceptance of cannabis as a therapeutic agent has been further hampered by its status as an illicit substance. ${ }^{5}$

\section{Cannabis}

Cannabis is related to the nettle and the hop and grows readily in a number of warmer climates worldwide. Marijuana (or marihuana) refers to the herbal preparation of the plant consisting of its dried leaves, small stems and flower heads. Hash

From the Office of Medical Bioethics (SAP), Department of Community Health Sciences (MJV), Department of Sociology (RAS), Department of Clinical Neurosciences (LMM), Faculty of Law (JCL), University of Calgary, Calgary, AB Canada

Received November 21, 2002. Acceptedin finalform March 25, 2003. Reprint requests to: Stacey A. Page, Room 93, HMRB, Office of Medical Bioethics, University of Calgary, 3330 Hospital Drive NW, Calgary, AB., T2N 4N1 Canada. 
is derived from the resin secreted by the leaves and flowers of the plant.

Cannabis contains over 400 compounds among which are nearly 100 cannabionoids. ${ }^{6}$ Delta-9-tetrahydrocannabinol $(\Delta$ ${ }^{9} \mathrm{THC}$ ) is the most abundant and the most potent psychoactive of these. Marijuana strength, measured by $\Delta^{9} \mathrm{THC}$ content, varies from strain to strain and is also affected by breeding, the conditions under which it is grown, its processing and storage. Expressed as the percent $\Delta^{9} \mathrm{THC}$, the potency has been found to vary from roughly 4 to $20 \%$. $^{7,8}$

Marijuana can be consumed in a number of ways: it can be smoked in cigarettes or pipes, eaten in foods, and extracted in teas or alcohol-based tinctures. Ingested, marijuana tends to have a slower onset of action, blunted high and longer duration of effect than when smoked. ${ }^{9}$

\section{EMPIRICAL DATA}

A survey distributed by the Alliance for Cannabis Therapeutics in the US and UK examined the perceived effects of smoked cannabis on MS symptoms (response rate 132/255). More than $70 \%$ of the subjects reported that cannabis reduced spasticity, chronic pain of the extremities, acute paroxysmal phenomena, tremor and emotional dysfunction. ${ }^{10}$

Two small clinical investigations have examined the effects of smoked cannabis on people with MS. The first, a case study, concluded that marijuana might have powerful beneficial effects on both spasticity and ataxia warranting further evaluation. ${ }^{11} \mathrm{~A}$ later study of 10 patients found that marijuana impaired objective ratings of posture and balance, although patients felt subjectively improved. ${ }^{12}$ Several very small clinical trials have compared the use of oral THC and/or nabilone, a synthetic cannabinoid, to placebo and have yielded varying results. ${ }^{13-18}$ Most participants reported at least subjective benefits and some investigations revealed objective improvements as well. ${ }^{13-17}$ The value of these results are limited by the small sample sizes, diversity in patient groups and dosing schedules, but collectively suggest that cannabis and/or its derivatives relieve symptoms of MS.

\section{Canadian Legal Context}

Under the Controlled Drugs and Substances Act, it is illegal to possess, seek and obtain, produce or traffic in cannabis, its preparations, derivatives or similar synthetic preparations.

Regulation of medicinal marijuana in Canada has been recently revised and the status of recreational cannabis use is under debate. In 2001, the Canadian government amended federal drug laws and the Medical Marihuana Access Regulations came into force. ${ }^{\S}$ These regulations permit people with certain illnesses to apply for an exemption to use cannabis medicinally. Those obtaining an exemption may obtain marijuana by growing their own, or by designating another person to grow it for them.

\section{Purpose}

Little is known about the extent of cannabis use among this patient group in Canada. This paper reports on a survey

${ }^{\S}$ SC 1996 c 19 as amended 2001 [SOR/2001-227] conducted in a sample of adults with MS in Alberta, Canada, and describes the prevalence and perceptions of cannabis use in this group prior to the implementation of the Medical Marihuana Access Regulations.

\section{METHODS}

The data for this study are derived from a larger survey that looked at the use of complementary and alternative medicine by people with MS.

Sample size determination: Calculations were based on estimating the proportion of MS patients who used complementary therapies to $\pm 5 \%$ with $95 \%$ confidence. Based on previous research, we conservatively estimated that complementary and alternative medicine is used by $50 \%$ of MS patients. ${ }^{19,20}$ To obtain our desired level of precision, a sample of approximately 390 people was needed. Allowing for a $50 \%$ response rate, 780 people were required for the survey.

Study population. The Calgary MS Clinic is the only regional source of neurological care and tertiary rehabilitation for patients with MS. At the time of sample selection, the clinic database contained information, including Expanded Disability Status Scale scores (EDSS), ${ }^{21}$ on 2600 people. Patients for whom an address was not known, those known to be deceased, and those who had not given blanket consent to be approached for research projects were dropped from the database. Exclusion criteria defined by the researchers were people under 18 years of age and those whose diagnosis was possible or probable MS (vs. clinically definite and lab-supported MS). After these exclusions, a sampling frame of 1335 remained. The database was then stratified by impairment level derived from the EDSS score yielding the distribution shown in Table 1. All people described as very severely impaired were included in the final sample as were the nine people for whom a score was not recorded. The remaining 742 subjects required were systematically and equally drawn from the remaining three impairment levels resulting in a total sample of 780 . The distribution of the study sample is also illustrated in Table 1.

Procedure. A covering letter, questionnaire and postage-paid return envelope were distributed by mail in June, 2000. To

Table 1: Distribution of sampling frame and study sample

\begin{tabular}{lcc}
\hline $\begin{array}{l}\text { Impairment level } \\
\text { (EDSS scores) }\end{array}$ & $\begin{array}{c}\text { sampling frame } \\
\text { (n) }\end{array}$ & $\begin{array}{c}\text { study sample } \\
\text { (n) }\end{array}$ \\
$\begin{array}{l}\text { No recorded score } \\
\text { None-mild impairment } \\
\quad \text { (EDSS 0-2.5) }\end{array}$ & 9 & 9 \\
$\begin{array}{l}\text { Moderate impairment } \\
\quad \text { (EDSS 3.0-5.5) }\end{array}$ & 545 & 240 \\
$\begin{array}{l}\text { Severe impairment } \\
\quad \text { (EDSS 6.0-8.0) }\end{array}$ & 367 & 241 \\
$\begin{array}{l}\text { Very severe impairment } \quad(\text { EDSS 8.5-9.5) } \\
\text { Total }\end{array}$ & 365 & 241 \\
\hline
\end{tabular}


Table 2: Demographic Information and Disease Characteristics

\begin{tabular}{lr}
\hline Sex & $(\mathbf{n}, \boldsymbol{\%})$ \\
$\quad$ Male & $106(26 \%)$ \\
Female & $309(74 \%)$ \\
Mean age -- years (SD) & $48(10.6)$ \\
Marital status (n, \%) & \\
$\quad$ Married/ common-law & $301(72 \%)$ \\
$\quad$ Never married/separated/divorced/widowed & $116(28 \%)$ \\
Education (n, \%) & \\
$\quad$ Less than high school & $40(10 \%)$ \\
High school or greater & $377(90 \%)$ \\
Employment status (n, \%) & \\
$\quad$ Working full/part-time & $128(31 \%)$ \\
On disability leave & $99(24 \%)$ \\
$\quad$ Retired/unemployed & $112(27 \%)$ \\
$\quad$ Student/homemaker & $74(18 \%)$ \\
Median family income & $\$ 50-\$ 59000$ \\
Mean age at diagnosis (SD) & $36(9.4)$ \\
Pattern (n, \%) & \\
$\quad$ Relapsing-remitting & $178(43 \%)$ \\
$\quad$ Secondary progressive & $97(24 \%)$ \\
Primary progressive & $41(10 \%)$ \\
Progressive-relapsing & $16(4 \%)$ \\
Did not know & $79(19 \%)$ \\
Disability & \\
Mild (fully functional, able to work) & $36(9 \%)$ \\
Moderate (limited independent walking ability) & $197(47 \%)$ \\
Severe (require walking aids/wheelchairs) & $156(37 \%)$ \\
Very severe (no functional use of limbs, confined to bed) & $28(34 \%)$ \\
Had a comorbidity & $253(60 \%)$ \\
Used conventional medication for MS symptoms & \\
& \\
& \\
& \\
&
\end{tabular}

enhance the response rate, a postcard reminder was sent out four weeks later.

Questionnaire. A self-report questionnaire developed for the purpose of the study was used to collect data. General sociodemographic information (e.g., marital status, age, sex, education) and information on disease characteristics (e.g., onset, diagnosis, pattern, symptom experience, disability, medication use, comorbidities) were collected. Questions regarding cannabis use assessed opinions on use, reasons for use, patterns of use and perceptions of effects. Questions were primarily close-ended although subjects were given the opportunity to provide additional detail in those cases where the response options provided did not contain a choice that described them.

For some questions, more than one response option could be endorsed. Finally, respondents were given the opportunity to make general comments about their experience with cannabis use.

Analyses. The survey data were entered into STATA $6 .^{22}$ Descriptive statistics were used to summarize responses. Multiple logistic regression was used to identify factors associated with cannabis use (alpha $=0.05)$. Content analysis was used to describe the textual comments.

The study was approved by the Conjoint Health Research Ethics Board at the University of Calgary.

\section{ReSUltS}

\section{Sample:}

Of the 780 surveys mailed, 107 were undeliverable (e.g., subjects had moved, were deceased). Four hundred and twenty people provided responses to the cannabis section (response rate $420 / 673=62 \%$ ), although the number responding to each question varies slightly. Sociodemographic and disease characteristics are illustrated in Table 2.

\section{Cannabis use:}

Most respondents believed that it should be legally permissible for people to use cannabis medicinally (72\%). Slightly less than one quarter $(23 \%)$ did not have an opinion, while the minority opposed $(5 \%)$. The vast majority stated they were aware cannabis was potentially useful in relieving symptoms associated with MS (96\%). Less than half of the respondents had tried cannabis at some point in their lives $(43 \%)$ and this was not necessarily for medicinal purposes.

The most common reasons given for not using cannabis by those who were aware it might be therapeutically useful but who had not tried it $(n=222)$ were: the fact it is an illegal substance (64\%), concern about side effects $(34 \%)$, lack of knowledge on how to obtain it (34\%) and a disbelief that it would help symptoms $(24 \%)$.

Considering those who stated they had tried cannabis $(n=176), 35 \% \quad(n=67)$ reported this had been to manage the symptoms of their MS. Among this latter group, 43 (64\%) had used it within the past three months (current users) and 24 (36\%) had discontinued use. The most common reasons endorsed for discontinuing use were cost $(n=11)$, dislike of side effects $(n=10)$, legal concerns $(n=8)$ and lack of effectiveness $(n=7)$.

Details of the experiences of current cannabis users are given in Table 3.

Multiple regression showed that cannabis users were not distinguished by marital status, education, or use of conventional medication. However, age, sex, disability level and income were predictive of cannabis use. Specifically, older people $(\mathrm{OR}=0.16$ : $95 \% \mathrm{CI}=0.057-0.45)$ and those with higher incomes $(\mathrm{OR}=0.19$; $95 \% \mathrm{CI}=0.070-0.52$ ) were less likely to use cannabis. Sex and disability interacted to predict cannabis use. Among those with less disability, women were significantly less likely to use cannabis $(\mathrm{OR}=0.17$ : $95 \% \mathrm{CI}=0.055-0.52)$.

Written comments were made by 35 respondents. Most comments contained descriptions of the symptom relief experienced with cannabis use. A couple of people contrasted the effects of cannabis with those of conventional medication. For example, one person described the following: "Pharmaceutical treatments that I've experienced have been extremely intoxicating (extreme anxiety, sleeplessness) among other symptoms that have been severely negative to my mental wellbeing as well as physical well-being (stomach trouble, breathing shortness). With cannabis, I feel more in control of my mind and body. If the effect is too strong, it is easily remedied by a cookie 


\section{Table 3: The experiences of current cannabis users}

\begin{tabular}{|c|c|}
\hline \multicolumn{2}{|l|}{ Decision to use cannabis prompted by: } \\
\hline Article/news story about cannabis & $6(15 \%)$ \\
\hline Suggestion from someone else with MS & $3(8 \%)$ \\
\hline Suggestion from family member/friend & $7(17 \%)$ \\
\hline Used recreationally: found out "by accident" & $24(60 \%)$ \\
\hline \multirow{2}{*}{\multicolumn{2}{|c|}{$\begin{array}{l}\text { Method by which cannabis was consumed: } \\
\text { Smoked }\end{array}$}} \\
\hline & \\
\hline as cannabis & $38(88 \%)$ \\
\hline as hash & $14(33 \%)$ \\
\hline Eaten (baked into brownies, cookies etc) & $6(14 \%)$ \\
\hline Drunk (as a tea) & $2(5 \%)$ \\
\hline \multicolumn{2}{|l|}{ Method by which cannabis was obtained: } \\
\hline Grown on own & $1(3 \%)$ \\
\hline Obtained elsewhere & $27(67 \%)$ \\
\hline Prefer not to answer & $12(30 \%)$ \\
\hline \multicolumn{2}{|l|}{ Frequency of cannabis use: } \\
\hline Less than $1 /$ day & $4(10 \%)$ \\
\hline $1 /$ day & $6(16 \%)$ \\
\hline 2-3 times/day & $7(18 \%)$ \\
\hline 4-6 times/day & $1(3 \%)$ \\
\hline varies considerably/use as needed & $20(53 \%)$ \\
\hline Median duration of use & 4 years (IQR 2,9) \\
\hline \multicolumn{2}{|l|}{ Symptoms perceived to be relieved: } \\
\hline Anxiety/depression & $29(67 \%)$ \\
\hline Spasticity & $25(58 \%)$ \\
\hline Chronic pain & $21(49 \%)$ \\
\hline Fatigue & $17(40 \%)$ \\
\hline Walking/balance problems & $14(33 \%)$ \\
\hline Tremor & $13(30 \%)$ \\
\hline Visual problems & $7(16 \%)$ \\
\hline Weight loss & $6(14 \%)$ \\
\hline Sexual problems & $6(14 \%)$ \\
\hline Bowel problems & $5(12 \%)$ \\
\hline Bladder problems & $4(9 \%)$ \\
\hline Memory loss & $2(5 \%)$ \\
\hline $\begin{array}{l}\text { Other relief reported (side effects of } \\
\text { conventional medication: headache, rash, } \\
\text { stomach upset) }\end{array}$ & $4(9 \%)$ \\
\hline \multicolumn{2}{|l|}{ Overall effect of cannabis on MS symptoms } \\
\hline Feel much better & $22(54 \%)$ \\
\hline Feel a little better & $16(39 \%)$ \\
\hline No change & $3(7 \%)$ \\
\hline
\end{tabular}

instead of hours of discomfort and anxiety from pharmaceutical treatments that take a long time to dissipate or level out. Cannabis is more effective and the dosage is easily controlled."

A few other people spoke about having tried cannabis in the past, but not liking the side effects. One person wrote "The marijuana seemed to help a fair amount with walking and stiffness. However the side effect of being 'high' was unacceptable (too much of a high)." Another person stated "I have nothing against pot or hash. I still wish I could. I have to take care of myself and being stoned and forgetting stuff can't be part of my life."
A number of comments pertained to the perceived need for medicinal use to be legalized. It was suggested that benefits of legalization would be a decreased crime rate, a drop in prices and greater control of the substance. A few respondents indicated that legalizing cannabis for medicinal use might just be a means of legitimating its recreational use.

A couple of people decribed the personal, moral dilemma they experienced when deciding whether or not to use cannabis medicinally. As written by one person: "I am not sure of the use of cannabis whether good or bad. There are days in my life when I would use it. Thankfully, these are few and far between. There was a time when I seriously considered using cannabis and purchased some. I still have it although have never used it and feel now I have it, I don't need or want to use it. There is a problem for me morally, I suppose or responsibly, I'm not sure but I can't use it. Knowing I now have it is enough."

\section{DISCUSSION}

A substantial proportion of those responding to the questionnaire stated they had used cannabis at some point in their lives $(43 \%)$. This is considerably higher than the $23 \%$ of Canadians reporting a similar pattern of use in a 1994 survey. ${ }^{23}$ This could be due to an actual increase in the proportion of people using cannabis generally, a trend that has been previously described, ${ }^{23}$ to people more readily disclosing use, or to people with MS being more likely to have used cannabis.

The majority of respondents stated they were aware that cannabis could be used medicinally for the treatment of MS and this is not surprising in light of the attention medicinal marijuana has received in the media recently. Most people (72\%) were of the opinion that marijuana should be legalized for medical purposes and this is consistent with previous surveys indicating the majority of Canadians $(78 \%)$ supported the federal government's plan of legalizing medical marijuana. ${ }^{24}$ This is in contrast to the smaller proportion of Canadians (27\%) who believe that cannabis should be legalized for recreational use. ${ }^{23}$

Despite knowing that cannabis might help relieve their symptoms, most people had not tried it because of its illicit status. The Medical Marihuana Access Regulations have been implemented to facilitate access for certain patient groups and it is probable that the proportion of people with MS who use marijuana will increase. For some people, however, the legal sanctions were not a deterrent as evidenced by the proportion of individuals who used cannabis prior to the introduction of these new regulations. In fact, for many, medicinal use evolved from previous recreational use. It is, therefore, likely that some people will use cannabis without applying for, or without being granted, an exemption.

Smoking was the primary method of cannabis consumption reported by users. Certain advantages have been ascribed to smoked, versus orally ingested cannabis or THC. THC is absorbed more rapidly and reliably from the lungs, allowing patients a greater degree of control in titrating their own doses. ${ }^{25,26}$ The presence of other constituents in cannabis smoke may modify the subjective experience of THC, reducing anxiety and other negative effects. ${ }^{27}$ However, as with tobacco, smoking cannabis may give rise to a host of respiratory problems ranging from irritation of the respiratory tract to malignancies. ${ }^{28}$ The development and evaluation of alternative delivery systems, such 
as nasal inhalers or skin patches, may be warranted if cannabis is found to be therapeutically effective.

Cost was the main reason cited for discontinuing use among those who had tried it for their MS but stopped. Although the new regulations permit people to possess cannabis, a legal supply still does not exist. While some people who have been granted exemptions grow their own, or have appointed a designate who has been granted an exemption to grow for them, these options are not always feasible given the equipment and expertise necessary to grow a sufficient, and healthy supply. ${ }^{29}$ Consequently, many still purchase the substance from others. Such transactions may be costly and may put purchasers at risk of buying a product of questionable quality. If cannabis is recognized as a medicinal product by the government, a legal supply should be accessible.

Dislike of side effects was the second most common reason endorsed for no longer using cannabis. Being able to enjoy cannabis, or use it effectively, has been described as a learned behavior. ${ }^{30}$ Indeed, in a previous survey of oncologists, it was observed that patients who had side effects using cannabis as an anti-emetic tended to be inexperienced with it. ${ }^{31}$ It has been recommended that new consumers be informed of the potential side effects prior to initial use in order to minimize anxiety when they are experienced. ${ }^{32}$ Similarly, it would seem important to take into consideration cannabis experience in future research.

Descriptions of the therapeutic benefits experienced with cannabis were consistent with those reported in earlier studies. ${ }^{10-12}$ In particular, subjects perceived reductions in spasticity and pain, and improved psychological well-being. These data are subjective and must be interpreted cautiously. They do suggest that further research is justified in evaluating the therapeutic properties of cannabis in people with MS.

Although lacking a firm evidence base, cannabis is being used as a medicine by people with MS. It will gain legitimacy within the medical arsenal with the establishment of its safety and efficacy, consistent with the standards applied to the development of other new drugs.

\section{ACKNOWLEDGEMENTS}

We thank all respondents for their time and effort. Funding for this study was provided by the Multiple Sclerosis Society of Canada.

\section{REFERENCES}

1. Weiner HL. A 21 point unifying hypothesis on the etiology and treatment of multiple sclerosis. Can J Neurol Sci 1998: 25: 93-101.

2. Svenson LW, Woodhead SE, Platt GH. Regional variations in the prevalence rates of multiple sclerosis in the province of Alberta, Canada. Neuroepidemiology 1994: 13: 8-13.

3. Metz L. Multiple sclerosis: symptomatic therapies. Semin Neurol 1998: 18: 389-395.

4. Beyerstein B. Alternative medicine: where's the evidence? Can J Public Health 1997: 88: 149-150.

5. Gray C. Legalize use of marijuana for medical purposes, MDs and patients plead. CMAJ 1998: 158: 373-375.

6. Gruber AJ. Marijuana and cannabinoid abuse. Pharmaceutical News 2000: 7: 30-32.

7. Voth EA, Schwartz RH. Medical applications of delta-9tetrahydrocannabinol and marijuana. Ann Intern Med 1997: 126: 791-798.
8. Smith DE. Review of the American Medical Association Council on Scientific Affairs Report on medical marijuana. J Psychoactive Drugs 1998: 30: 127-136.

9. Ashton CH, Morgan DR (Eds). Therapeutic uses of cannabis. Amsterdam: British Medical Association. 1997.

10. Consroe P, Musty R, Rein J, Tillery W, Pertwee R. The perceived effects of smoked cannabis on patients with multiple sclerosis. Eur Neurol 1997: 38: 44-48.

11. Meinck HM, Schonle PW, Conrad B. Effect of cannabinoids on spasticity and ataxia in multiple sclerosis. J Neurol 1989: 236:120-122.

12. Greenberg HS, Werness SAS, Pugh JE, et al. Short-term effects of smoking marijuana on balance in patients with multiple sclerosis and normal volunteers. Clin Pharmacol Ther 1994: 55: 324-328.

13. Petro DJ, Ellenberger C. Treatment of human spasticity with delta9-tetrahydrocannabinol. J Clin Pharmacol 1981: 21: 413S-416S.

14. Clifford DB. Tetrahydrocannabinol for tremor in multiple sclerosis. Ann Neurol 1983: 13: 669-671.

15. Ungerleider JT, Andyrsiak T, Fairbanks L, Ellison GW, Myers LW. Delta-9-THC in the treatment of spasticity associated with multiple sclerosis. Adv Alcohol Subst Abuse 1988: 7: 39-50.

16. Martyn CN, Illis LS, Thom J. Nabilone in the treatment of multiple sclerosis. Lancet 1995: 345: 579.

17. Brenneisen R, Egli A, Elsohly MA, Henn V, Spiess Y. The effect of orally and rectally administered delta-9-tetrahydrocannabinol on spasticity: a pilot study with 2 patients. Int J Clin Pharmacol Ther 1996: 34: 446-452.

18. Killestein J, Hoogervorst EJL, Reif M, et al. Safety, tolerability and efficacy of orally administered cannabinoids in multiple sclerosis. Neurology 2002: 58: 1404-1407.

19. Stenager E, Stenager EN, Knudsen L, Jensen K. The use of nonmedical/alternative treatment in multiple sclerosis: a 5 year follow-up study. Acta Neurol Belg 1995: 95: 18-22.

20. Pleines J. Multiple sclerosis and alternative medicine. Axon 1992: 13: 123-124.

21. Kurtzke JF. Rating neurologic impairment in multiple sclerosis: an expanded disability status scale (EDSS). Neurology 1983: 33: 1444-1452.

22. Stata statistical software: release 6.0 [computer program]. College Station TX: Stata Corporation: 1999.

23. Canadian Center on Substance Abuse (CCSA). Canadian profile: alcohol, tobacco and other drugs, Ottawa. CCSA. 1999.

24. Arnold T. Canadians favour the use of medical marijuana. National Post 138 Ed. 1999 Apr 7; 1.

25. Chang AE, Shiling DJ, Stillman RC, et al. Delta-9tetrahydrocannabinol as an antiemetic in cancer patients receiving high-dose methotrexate: a prospective, randomized evaluation. Ann Intern Med 1979: 91: 819-824.

26. Ohisson A, Lindgren AE, Whalen A. Plasma delta-9-tetrahydrocannabinol concentrations and clinical effects after oral and intravenous administration and smoking. Clin Pharmacol Ther 1980: 28:409-416.

27. Zuardi AW, Shirakawa I, Finkelbarb E, Karniol IG. Action of cannabidiol on the anxiety and other effects produced by delta-9THC in normal subjects. Psychopharmacology 1982: 76: 245250.

28. Hall W, Solowij N. Adverse effects of cannabis. Lancet 1998: 352: 1611-1616.

29. Feldman HW, Mandel J. Providing medicinal marijuana: the importance of cannabis clubs. J Psychoactive Drugs 1998: 30: 179-186.

30. Stebbins RA. Tolerable differences: living with deviance. 2 nd ed. Toronto: McGraw-Hill Ryerson Limited; 1996.

31. Doblin RE, Kleiman MAR. Marijuana as anti-emetic medicine: a survey of oncologists' experiences and attitudes. J Clin Oncol 1991: 9:1314-1319.

32. Sibbald B. A primer for patient's use of medical marijuana (news). CMAJ 2001: 165: 329. 